\title{
Engineering Elective Course Re-design to Promote Student Engagement
}

\author{
Gordon D. Stubley \\ Mechanical and Mechatronics Engineering, University of Waterloo \\ stubley@uwaterloo.ca
}

\begin{abstract}
Computational Fluid Dynamics (CFD) for Engineering Design, is a $4^{\text {th }}$ year mechanical engineering elective course. The course goal is for course graduates to be able to effectively use computer simulation tools to select optimal engineering designs based on the analysis of fluid flow performance. After being well received for many years, over several course offerings the class attendance, the student engagement in lectures, the student demonstration of key course concepts in the final summative project, and the student course evaluation scores all dropped.

From student feedback to specific questions during the student course evaluation it was found that the students believed that their existing understanding of engineering fluid mechanics was sufficient to make well-informed design decisions and that the emphasized course concepts were not relevant to the engineering design process. This feedback informed a course re-design.

After briefly describing the course context and objectives and the motivation theory that guided this course redesign, the two major features of the course re-design, pre/post-test activities and authentic engineering assignments, are described in some detail. Finally the impact of the re-design on student performance and outcomes from three offerings of the re-designed course is presented.
\end{abstract}

Keywords: course outcomes assessment, pre/post testing, authentic assessment, student motivation

\section{INTRODUCTION}

ME 566, Computational Fluids Dynamics (CFD) for Engineering Design, is an elective course offered in the first semester of the fourth year mechanical engineering program. The mechanical engineering fluids engineering curriculum has two core fluid mechanics courses that are offered in the first and second semesters of third year. After taking ME 566 students will typically take one or more fluids engineering electives in the second semester of fourth year from offerings that include aerodynamics, turbomachinery, fire safety engineering, air pollution, and experimental fluid mechanics.

ME 566 has three goals or objectives:

1. To develop an enriched understanding of complex fluid flows. Specifically students should be able to analyse a simulation or a set of experimentally measured flow values to determine the significant flow processes and then be able to identify how the significant flow processes impact flow design performance. Students should be able to select an optimal flow design from a set of flow design alternatives;

2. To provide sufficient understanding of CFD algorithms for students to be able to quantify and control modelling error in a CFD analysis; and

3. To provide an opportunity for students to complete a flow analysis project and to present the results in a concise and complete report.

During the term students submitted five assignments that were graded for $50 \%$ of the course grade. The major summative activity was a CFD analysis project. The project was based on an experimental flow from the literature such as the study of mixing in confined jets of Liou et al [2]. Students were asked to evaluate the change in some aspect of the flow geometry, such as the angle of the back wall in the Liou et al study, and to determine the impact of this change on the flow performance. Students submitted a professional technical report documenting their model set up, its validation, and their findings. The report was graded for $40 \%$ of the course grade. The remaining $10 \%$ of the course grade was split equally between a grade for class participation (5\%) and an oral interview on the project's findings (5\%).

In the 2010 and 2011 offerings of ME 566 there were three indications that students were not engaging in the course as students had in previous offerings:

- Student reaction: The student perception of the quality of instruction in the course as measured by the student course evaluation survey scored as 85 and 78 for the 2010 and 2011 offerings. The comparable average score for the previous 6 offerings was 93; 
- Student attendance rate in lectures went from being consistently well above $80 \%$ from 2003 to 2009 to between 40\% and 50\% in 2010 and 2011. In the 2011 offering this low attendance rate set in by the end of the first week of lectures;

- In the 2011 offering, $73 \%$ of the students compared simulations based on the flow in proposed modified geometry to the experimental results based on the flow in the base geometry. These comparisons were incorrectly used to validate the CFD models indicating that a significant fraction of the class did not understand the impact that geometry can have on flow and the errors that can potentially arise in CFD modelling.

Based on these three indicators a re-design of the portions of the course was undertaken. In the remaining sections of this paper the basis for establishing the focus and nature of the course changes is reviewed, the two major course features of the re-design are then presented, and the paper closes with a review of the impact of the course changes on student engagement and course outcomes.

\section{BASIS FOR COURSE REDESIGN}

\subsection{Focus Group Feedback}

As part of the student course evaluation process in the 2011 offering of the course, the students present for the course evaluation were asked to comment on why they believed that their colleagues had not attended lectures and to identify any weaknesses they perceived in the lectures and homework. While this particular group of students had regularly attended lectures, as has already been noted, they still perceived a relatively lower quality of instruction in the course than students in previous terms had perceived.

In the student feedback the three major themes reported were:

i. There was too much emphasis on fluid mechanics theory since they had already completed two courses on fluid mechanics;

ii. The lecture material was largely irrelevant because it did not directly increase the student skill in the CFD software; and

iii. The grading of assignments appeared to be arbitrary in that credit was not given for discussion points that appeared to be true to the students.

\subsection{Motivational Theory Framework}

As part of the analysis of the student feedback, Svinicki's [3] amalgamated theory of learning motivation based on modern cognitive motivational theory was reviewed. This theory suggests that there are two necessary conditions for students to be motivated to engage in particular learning activities.

Firstly, students have to see value in achieving the goals of the learning activity. Students will see value in a learning activity that is relevant to their perceived future career activities, is interesting, has sufficient intrinsic and extrinsic rewards, develops recognizable skills and knowledge, allows elements of individual control and ownership, and is appreciated by others. While a particular activity does not have to address all these aspects of increasing or demonstrating value, enough of the aspects have to be present to ensure that students with a variety of personal goals and backgrounds will see value in the activity. In the ME 566 context, career relevance is a crucial aspect that should be addressed because all of the students will have completed between four and six cooperative education work terms and will therefore have had significant exposure to the engineering workplace and its priorities.

Secondly, students have to perceive that they can realistically complete the learning activity and achieve its intended goals before they will engage in the activity. The student expectation of achievement is affected by the level of challenge of the activity, their previous experiences with similar activities in the course and in other courses, possibly in other disciplines, the sense of expectation and encouragement in the learning environment, and established attributes of the students including their inherent self-efficacy and inherent beliefs on the nature of learning abilities.

With this framework, it can be seen that the student feedback identified a lack in both conditions necessary to ensure motivation. The perceived over-emphasis on fluid mechanics and irrelevancy of the lecture material speaks to the value of learning outcomes and their associated activities. The perceived arbitrariness in the assignment grading speaks to the expectancy of achievement. The changes to the course design presented in the next section were developed to ensure that there were activities which ensured that students could clearly and directly see the value in the intended learning outcomes and that with reasonable effort that they could achieve these outcomes.

\section{RE-DESIGNED COURSE FEATURES}

\subsection{Maintained Course Design Features}

As mentioned in the introduction, prior to $2010 \mathrm{ME}$ 566 had a long standing record as a successful course with good student learning outcomes and a high student perception of quality of instruction. Therefore, the course re-design recognized that the basic structure of the course 
was sound and did not need significant modifications. In particular the intended learning outcomes and the summative course project were maintained with little change. Discussions with engineers working on CFD development and support for ANSYS Canada Ltd. confirmed that the intended learning outcomes were relevant to expected engineering practice and that the summative project was an authentic engineering activity.

\subsection{Pre-test Activities}

While both the course instructor and engineers practicing in the CFD field agreed that the intended course outcomes were relevant to engineering practice, it was clear that the students did not perceive this relevance. From the student feedback, the student perception of irrelevance was based on their perception that they had sufficient understanding of fluid mechanics and that effective engineering practice only required skill in operating the CFD software.

The first component of the course re-design was to begin each significant course section with a pre-test activity. The use of pre-test activities in higher education STEM disciplines was first promoted by Halloun and Hestenes [1]. In their pioneering work they demonstrate that having students directly confront a misunderstanding is a necessary step in the learning process if students are going to develop deep expert knowledge in disciplines.

In ME 566 the pre-test activities were designed to test an ability or knowledge that students would readily agree as being relevant in engineering practice and that from previous experience in the course were likely to be poorly done before the course instruction and learning activities.

A good illustration of a pre-test activity is the duct design sketching activity held in the first lecture to provide motivation for all the course activities. As shown in Fig. 1, students are asked to design and sketch an optimal shape for a $90^{\circ}$ curved diffuser. Almost universally, students will sketch in a smooth geometry for the bend. Fig. 2 shows the typical geometry sketched by the students. Also, almost universally, the students will not sketch in any details such as streamlines and pressure variations in the anticipated fluid flow through their suggested design. Even without showing the students the simulated flow field through their proposed design, Fig. 2, or the simulated flow field through a design that ensures a smooth flow without separation, Fig. 3, it is easy to have the students recognize that in spite of having taken two courses in fluid mechanics they used no knowledge of fluid mechanics when confronted with a fluid mechanics design challenge. Indeed the sketch that they make at the start of this $4^{\text {th }}$ year elective course is probably identical to the sketch they would have made if asked to do this activity as they entered $1^{\text {st }}$ year. Twelve such activities are run throughout the course. Some were assigned as homework activities and some were done in class.

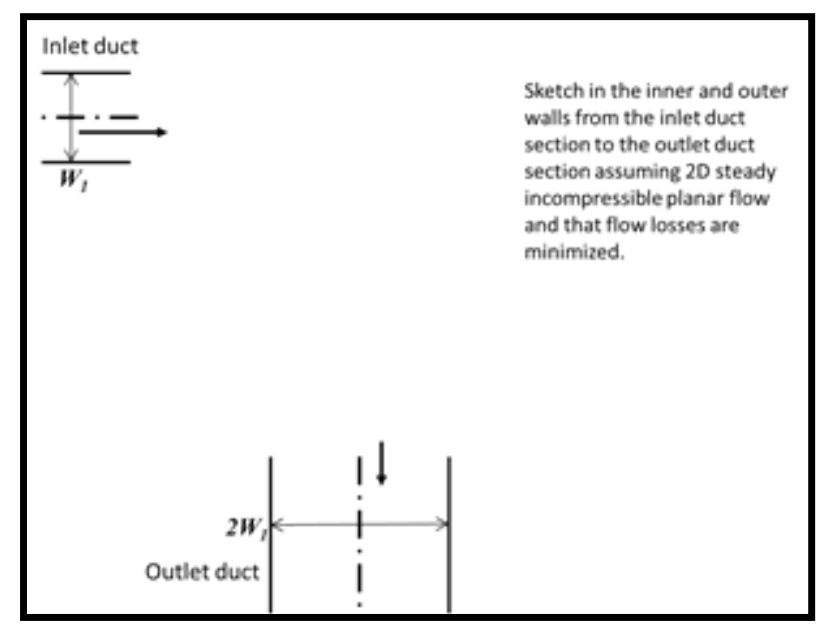

Fig. 1. $90^{\circ}$ diffuser design sketching activity given at the start of ME 566.

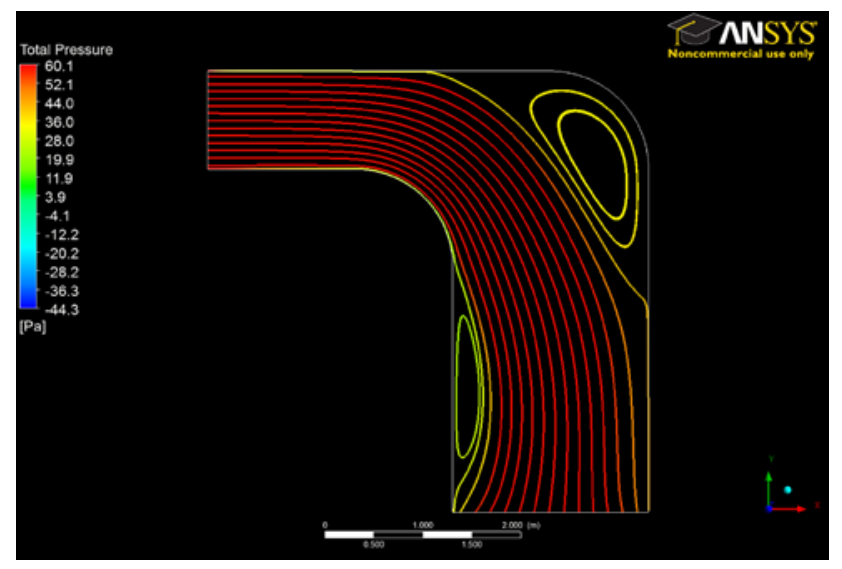

Fig. 2. Simulated flow through a typical student design based on smooth geometry changes.

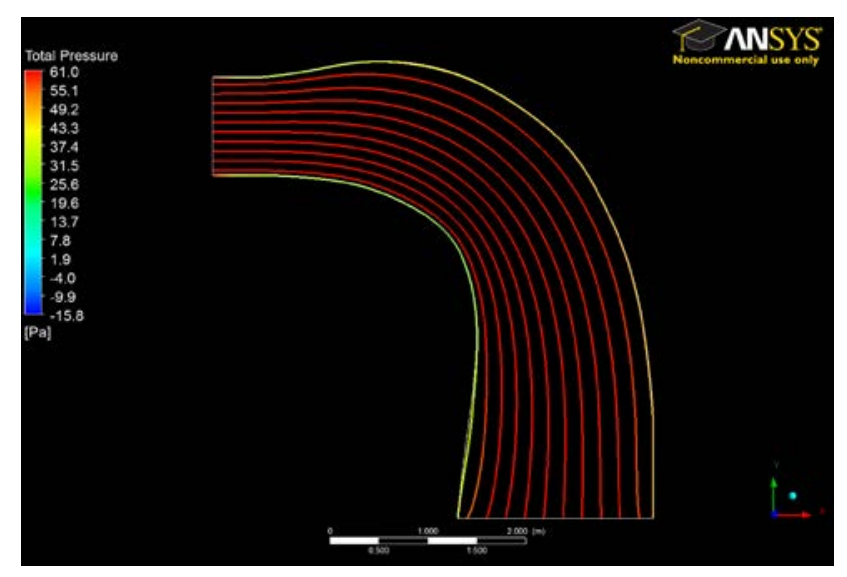

Fig. 3. Simulated flow through an optimal design based on minimizing flow separation. 


\subsection{Authentic Homework}

The second major focus of the course design was the homework assignments. For the 2011 and earlier offerings there were five homework assignments:

1. Spreadsheet analysis of pipe network flow review of basic 1D fluid mechanics concepts

2. CFD simulation - following a tutorial on the use of ANSYS CFX independently complete a prescribed CFD simulation and analysis of developing duct flow

3. Analysis of flow over a backstep - given CFD simulations of laminar and turbulent flows over a backstep analyse the flows to determine dominant flow processes

4. Finite volume computational molecule - given local flow and mesh properties explain the relative size of the coefficients in the computational molecule

5. Iterative convergence errors - analyse the iterative convergence of simple $1 \mathrm{D}$ heat flow in a fin to distinguish iterative solution residual, iterative solution error, and solution error.

The emphasis in grading each homework assignment was on assessing the course theoretical concepts. As discussed in the introduction, students perceived the grading to be arbitrary and would often comment that they did not know what was expected of them.

The homework assignment re-design was aimed to ensure that students saw both the value through relevance of the homework activity and were confident in their expectancy of achievement. These two characteristics were achieved by giving each homework (except the last and shortest homework) an authentic design question to be answered giving each homework a clear and easily understood outcome. For example, in the third homework students were still expected to analyse simulated laminar and turbulent flows over a backstep. In the re-designed format they were asked to write a two page technical memorandum to their supervisor determining the effectiveness of replacing the backstep geometry with a gradual straight walled diffuser geometry. This engineering design question provided an authentic focus to the activity and also gave a tangible goal to the work to guide student focus.

A secondary aspect of the homework assignment redesign was that all the major skills and judgements required to successfully complete the summative course project were practiced in the course homework assignments (which were often practiced in the pre-test learning activities). As a result students had opportunity to practice and receive feedback prior to beginning the summative project.

In recognition of the increased learning activities and reduction in the number of homework assignments the homework assignments contributed to $40 \%$ of the course grade (down from 50\%) and class participation contributed to $15 \%$ of the course grade (up from $5 \%$ ). The project and oral interview grade contributions remained at $40 \%$ and $5 \%$ respectively.

\section{RE-DESIGN OUTCOMES}

Did the changes in the course have any impact? To assess the potential impact student learning and reaction was monitored in course offerings with the re-designed course components.

\subsection{Student Learning}

One key indicator of the student learning outcomes from the course is their understanding of the difference between CFD model validation and flow design performance assessment which can be assessed in the summative project. Students with a deep understanding of potential CFD modelling errors and of the factors that affect flow performance will develop a CFD model with the base geometry to compare to the experimental results obtained from flow in the same base geometry. The impact of any flow geometry change on flow performance will be assessed by comparing the CFD simulations for flow through the modified geometry to the CFD simulations for flow through the base geometry. As mentioned in the introduction, a common potential student error is to just do a CFD simulation for the modified geometry and to compare this single simulation to the experimental results to both validate the CFD model and to estimate the impact of the modified geometry on flow performance.

Table 1 shows the fraction of the class that use the base geometry simulations and the modified geometry simulations to validate the CFD model. The Spring 2011 is prior to the course redesign and approximately $3 / 4$ of the class incorrectly used the modified geometry simulations for CFD model validations. For the three course offerings following the course re-design, between $2 / 3$ and $3 / 4$ of the class are correctly using simulations through the base geometry for CFD model validation.

While this improvement is significant and noteworthy, it is still disappointing that there is a sizable fraction of the class incorrectly using the simulations through the modified geometry. One possible explanation is that students are reluctant to generate two geometry models because of the challenges associated with mesh 
generation. In the 2014 offering this issue was directly addressed by incorporating a new set of tutorials that better developed student skill in mesh generation and in working with multiple CFD models. However as the results in Table 1 show this had no positive impact on the student learning as indicated by their choice of geometry for CFD model validation.

Table 1: Student choice of geometry for CFD model validation in the final project.

\begin{tabular}{|l|c|c|c|}
\hline \multicolumn{1}{|c|}{ Term } & $\begin{array}{c}\text { Class } \\
\text { Size }\end{array}$ & $\begin{array}{c}\text { Base } \\
\text { Geometry }\end{array}$ & $\begin{array}{c}\text { Modified } \\
\text { Geometry }\end{array}$ \\
\hline Spring 2011 & 33 & $27 \%$ & $73 \%$ \\
\hline Fall 2012 & 25 & $76 \%$ & $24 \%$ \\
\hline Fall 2013 & 35 & $66 \%$ & $34 \%$ \\
\hline Fall 2014 & 34 & $65 \%$ & $35 \%$ \\
\hline
\end{tabular}

\subsection{Student Reaction}

A second indicator of the impact of the course redesign is the student reaction to the course learning activities as measured by their engagement in class lectures and by their perceptions of the quality of instruction. Table 2 shows the class size, response rate for the student course evaluations (a measure of class attendance since the evaluations are held in lectures), and the student perception of the quality of instruction (answer to the question "What is your overall appraisal of the quality of teaching in this course" on a five point Likert scale from very high - 100 to very low - 0). For the six offerings prior to 2010 the averages for the six offerings are given.

Table 2: Student response rate and score for perceived quality of instruction in the student course evaluation.

\begin{tabular}{|l|c|c|c|}
\hline \multicolumn{1}{|c|}{ Term } & $\begin{array}{c}\text { Class } \\
\text { Size }\end{array}$ & $\begin{array}{c}\text { Response } \\
\text { Rate }\end{array}$ & $\begin{array}{c}\text { Quality of } \\
\text { Instruction }\end{array}$ \\
\hline 2003-2009 & 22 & $91 \%$ & 93 \\
\hline Spring 2010 & 37 & $46 \%$ & 85 \\
\hline Spring 2011 & 33 & $45 \%$ & 78 \\
\hline Fall 2012 & 25 & $85 \%$ & 94 \\
\hline Fall 2013 & 35 & $89 \%$ & 88 \\
\hline Fall 2014 & 34 & $86 \%$ & 94 \\
\hline
\end{tabular}

For the three offerings following the course re-design (2012 - 2014) class attendance as measured by response rate and the student perception of the quality of instruction are significantly above those measured during the 2010 and 2011 offerings. Student written comments for the 2012 to 2014 offerings were consistent with these quantitative measures.

\section{SUMMARY}

The positive increases in an indicator of student learning outcomes, in student attendance, and the student perception of the quality of instruction consistently demonstrate that the implementation of pre-test learning activities and authentic homework assignments has been effective in ME 566. While these positive increases are noteworthy, there is still potential for further improvement in student learning. In future work the use of student ePortfolios will be investigated as a mechanism to ensure that students better retain and apply course concepts and skills they have practiced throughout the course.

\section{Acknowledgements}

Discussions with Drs. Stephen Reuss and Phil Zwart of ANSYS Canada Ltd. have ensured that the ME 566 learning outcomes are relevant for engineering practice and that the summative course project is an authentic activity. The support of Mechanical and Mechatronics Engineering department in providing sufficient licences of ANSYS CFX and augmented teaching assistant resources is gratefully acknowledged.

\section{References}

[1] I.A. Halloun, and D. Hestenes, Common sense concepts about motion, American Journal of Physics, Vol. 53, No. 11, pp. 1056-1065, 1985. Available as of April 14, 2015 from http://dx.doi.org/10.1119/1.14031

[2] T.-M. Liou, K.-L. Hsiao and M.-K. Tsai, Experimental and theoretical studies on turbulent mixing of confined jets, Common Sense Concepts about Motion, Int. J. Heat and Fluid Flow, Vol. 12, No. 3, pp. 210-217, 1991. Available as of April 14, 2015 from http://dx.doi.org/10.1016/0142727X(91)90054-Y

[3] M.D. Svinicki, Learning and Motivation in the Postsecondary Classroom, Jossey-Bass Publishing, 2004, 263 pp. \{ISBN: 978-882982-59-2\} 